\title{
Building Collaborative Learning Opportunities between Future Veterinary and Design Professionals
}

\author{
Fernando Magallanes ${ }^{1}$, Michael K. Stoskopf ${ }^{2}$, Kenneth D. Royal $^{2}$ \\ ${ }^{1}$ Department of Landscape Architecture, College of Design, North Carolina State University, USA \\ ${ }^{2}$ Department of Clinical Sciences, College of Veterinary Medicine, North Carolina State University, USA \\ Correspondence: Fernando Magallanes, Department of Landscape Architecture, College of Design, North Carolina \\ State University, USA
}

Received: June 8, 2015 Accepted: June 10, 2015 Online Published: June 25, 2015

doi:10.11114/jets.v3i5.852 URL: http://dx.doi.org/10.11114/jets.v3i5.852

\begin{abstract}
Positive inter-professional collaborations and interactions facilitate the effectiveness of veterinarians working on professional teams addressing a wide range of societal challenges. The need for these interactions extend far beyond the different medical professions, which is the limit of many discussions of inter-professional relations for veterinary medicine. Methods of problem solving differ across professions, and clinical veterinary problem solving is quite distinct from the approaches of non-medical professions. These distinctions are particularly obvious when looking at the approaches of design professionals. Yet, most veterinarians work in collaboration with architects and landscape architects at some time in their careers, with varying degrees of success. This case study describes a collaboration between a College of Veterinary Medicine and a College of Design in which a course was offered across both colleges that allowed students to build a real life design to suit the needs of a veterinary medical college considering how to best utilize space for animals, animal and human interaction and the holistic development of healthy spaces for humans. Results of the collaboration indicated that despite initial struggles, students from very different disciplinary backgrounds were able to effectively work in teams, problem solve, communicate and exchange ideas, learn to appreciate their peer counterparts, and produce a high-quality design that may ultimately be adopted by the university.
\end{abstract}

Keywords: veterinary education, landscape architecture, design process, interdisciplinary education, veterinary medicine, case study

\section{Introduction}

\subsection{Introduction of the Problem}

Like all other professions, the veterinary profession does not operate in a vacuum. Thus, there is a strong need for veterinarians in all forms of veterinary professional activity to interact with other professionals (Kustritz et al 2013; Whitaker 2014). The unique aspects of veterinary education in doctor of veterinary medicine (DVM) programs are both a strength and a limitation for the profession. Carefully developed to optimize approaches to clinical assessment and problem solving, veterinary "thinking" is different from the approaches of most other professions, and those differences can impede communication and understanding necessary for an excellent outcome in collaborations. Early experience with inter-professional communication and collaboration provides a bridge that facilitates efficient and effective interactions providing for quicker effective team building and better project outcomes.

The importance of positive and productive inter-professional collaborations and interactions has been highlighted by the re-emergence of the One Health concept. The focus of medical doctorate (MD), public health and health ecology curricula prepare highly intelligent individuals with markedly different perspectives on the approach to health management. Bringing these divergent viewpoints together effectively is not a trivial task even with such closely related areas of interest (Interprofessional Education Collaborative Expert Panel, 2011). However, the benefit of positive inter-professional interactions extends far beyond interactions with human medicine and ecosystem health professionals.

\subsection{Need for Collaboration}

A vast body of literature has demonstrated the benefits of interdisciplinary collaborations. However, as noted above, the 
veterinary profession often operates in silos. Interestingly, nearly every veterinarian will at some time in their career find themselves involved in a project with design professionals, architects and landscape architects. For those in some disciplines the interactions will be extensive. For example, zoological medicine veterinarians will find themselves on exhibit and facilities design teams fairly constantly throughout their career. For others, the interactions may be less numerous, but nevertheless, defining of their career success, such as for general practitioners and clinical specialists who build their clinics and hospitals to support their practice. For others, it may be limited to the construction of a dream home.

To date, the lack of collaborations between veterinarians and design professionals has also resulted in a relatively weak toolbox of understanding of what is important in design of space of human animal interactions. Solutions to veterinary related design are often based on time worn "tried and true" solutions that do not benefit from advances in understanding of design possibilities, whether in materials and technology, or based on improved understanding of the needs of humans or animals.

On the other side of this equation, there is a strong need for design professionals who are able to effectively utilize the understanding that veterinarians bring to the needs of both animals and humans in the design of places for animals and humans to interact, be this hospitals, clinics, husbandry facilities, exhibits, educational facilities, etc. The exercise in inter-professional collaborations strengthens both professions in the sense that it improves the final product of collaboration, but also generates professionals in each discipline that have enhanced experience and skill in delivering the best solutions to future collaborative projects.

Increased collaborations between veterinary schools and colleges of design have the potential to create the intellectual capital needed to catapult design of spaces where humans and animals come together to another plane. This can be accomplished as highly educated designers become aware of the opportunities and also the need for better design of human/animal shared spaces (from veterinary hospitals to homes that have pets), and veterinarians learn the basis of design process and become more facile in both thinking about the implications of structure and form on life and well-being and in communicating what they know to design professionals.

The relative professional isolation of veterinary medicine can result in the talents and insights of the profession being overlooked when veterinarians could provide valuable advice or leadership on a wide range of challenges facing society. This effectively translates into limited professional opportunities. Veterinarians have unique and extensive understanding of a broad range of issues, particularly as they relate to health, be it preventative maintenance, or identification of infectious or non-infectious perturbations of health. They also understand animals, whether they be valuable production, beloved pet, important key species in biodiversity, or nuisance pest animals. Yet it is still unusual to find veterinary expertise incorporated in teams tasked with solving challenges where veterinary expertise would be valuable. In the realm of design, this is in part related to an unfamiliarity of design professionals with the experience and knowledge bases of veterinarians. It is also driven, however, by a dearth of veterinarians who have developed the perspectives and understanding required to work effectively with design professionals in a collaborative approach to projects that address human/animal interactions and needs. Interestingly, even within the broader profession of design, many students rarely collaborate with individuals from different design specialties. Research has indicated that collaborations occurring across design specialty areas are often tumultuous and challenging (Kim, Ju \& Lee, 2015). Therefore, it stands to reason that interdisciplinary collaborations across very different disciplines may present even more challenges due to the considerable effects of disciplinary norms and conventions (Angelo \& Cross, 1993; Lee, 2004; Royal, 2010; Royal, Eli \& Bradley, 2010).

Thus, the purpose of this case study was to describe a collaboration across two disparate disciplines and discuss the lessons learned. Our hope is that professionals working in a wide variety of academic disciplines may be able to anticipate some of the issues we experienced and will subsequently be able to prepare accordingly so as to minimize conflict, increase learning opportunities, and successfully meet the established goals for the course.

\subsection{Case Study Approach}

For the present study, we present a case from a collaborative project between a College of Veterinary Medicine and a College of Design at North Carolina State University. We provide a thorough description of the collaborative project and assess the effectiveness of the collaboration by examining faculty observations, students' work products, and students' reflections on the value of the experience and utility of the course.

\section{Method}

\subsection{Description of Collaborative Project}

The North Carolina State University has both a prominent College of Veterinary Medicine (CVM) and a highly regarded College of Design (COD). Both colleges are successful in their respective disciplines, but have rarely worked 
together in the past. The collaboration began when two friends and colleagues, a veterinarian and a landscape architect, began to discuss the need for greater understanding of, and creativity in the development of spaces for animals and in particular spaces where humans and animals interacts in an educational environment. Fueled by shared interests that could be focused on an identified instructional space need at the College of Veterinary Medicine's campus, the idea of introducing students to interdisciplinary learning arose as a way to enhance student skill sets and inter-professional understanding while generating creative approaches to a novel project. After early collaborative efforts in 2012 by faculty of both colleges and the gathering of key data resources by select students in Fall semester of 2012, a novel inter-professional learning experience in the form of an experimental combined studio course was taught in Spring semester of 2013.

\subsection{Course Description}

The purpose of the project was to bring together advanced design and veterinary students in a collaborative atmosphere, looking at real life problems in design of infrastructure for the teaching of zoological medicine in a DVM program. The project was a combined studio course that sought to develop the basis for moving towards an integration of a teaching animal unit with zoological species (Zoological Teaching Animal Unit) into the teaching resources of the CVM. A mantra was "students designing for students". Veterinary students generally attended sessions in the late afternoon after their veterinary classes. The studio was set up to accommodate the fact that Friday afternoons were frequently available for veterinary student participation - based on the DVM curriculum structure. The course was co-taught by a veterinarian and a landscape architect with collaboration of an architect.

\subsection{Course Project}

The original goal of the class project was to bring DVM students and COD Master of Landscape Architecture (MLA) students together to design an improved habitat enclosure for a wild carnivore facility housing red wolves in a program that was intending to grow with additional wild carnivore species. This goal quickly changed scope. The original existing enclosure functions as part of the Teaching Animal Unit (TAU), which was created as a way of training and educating the many urban individuals seeking veterinary careers who have no or very limited farm animal or zoologic species experience. The wild carnivore facility is part of a subcomponent of the TAU, the Zoological Teaching Animal Unit (ZTAU), which focuses on providing experience working with wild animals. The ZTAU supports a vision of a much expanded role of the veterinary profession in the health management of wildlife and zoological species in the future, and with that vision there was a need to plan for facilities to support avian, carnivore, and aquatic species well into the future. It was in this early pre-studio phase of the project that the importance of solid inter-professional collaboration became very apparent. Though the veterinary perspective was very focused on individual projects and species, design professionals were more focused on the scope of both the TAU and the philosophy of the ZTAU.

It became readily apparent that to best develop the individual projects over time, it was important to develop a strong basis for careful, long-term site planning. Specifically, this involved the development of a land plan that would account for future uses developed over time as needed by the CVM. The ZTAU philosophy is to utilize land in an environmentally sound manner and to focus on land that is unsuitable for traditional livestock production activity. The facilities being considered were a completely new type of facility that had not been developed prior to this undertaking, and we could not start designing specific habitats without a better understanding of the conceptual idea about how the new ZTAU facilities were intended to work with the existing TAU facilities. Specific details about available land types, and infrastructure, in addition to information about specific sites, such as sizes for enclosures, desired species and numbers of animals, etc. needed to be integrated. The combined studio course project concept rapidly morphed from an individual facility design project into a broader scale site plan development project to support the long term development of the ZTAU.

\subsection{Phase I}

The early beginnings of the project began with three months of preparation and information gathering in a semester long independent studies with the collaborative instructors. Additionally, two MLA and two DVM students were involved and provided three months of preparation and information gathering support in a semester long special studies course. Select students from each college were enrolled in special studies classes in their respective colleges in the fall semester ahead of the main combined studio course. These students were sought out by the faculty and selected based on their advanced status in their respective programs and their personal interests in designing for animals. These students also assisted the faculty for the combined studio course prepare for the spring course. Students conducted surveys of the needs of the broader ZTAU faculty involved in teaching veterinary students across all zoological species, to help develop the broader scale of the ZTAU mission. They also gathered key site and basic species data needed to support the main combined studio class the following semester. They were also actively involved in recruiting other students to participate in the main studio course scheduled for the spring semester. 


\subsection{Phase II}

After fall planning activities were completed, students were recruited from the second and third year classes of the College of Veterinary Medicine's DVM program (8) and senior status graduate students (6) in the College of Design's Landscape Architecture Master's program (MLA). The Design Team members from the MLA program were not all at the same skill level, but each student did have the knowledge about all the things that a landscape architect needs to know to participate in a design project. They included the two LA students who participated in the fall special studies course. The MLA students brought skills to the project that included use of video, computer graphics, site grading, design drawing, and an understanding of the design process. DVM students were similarly heterogeneous in experience, and included the DVM students who participated in the fall course. The DVM students brought to the project strong science backgrounds and biological knowledge about and some experience of having worked with many of the species considered in the broad scoped design studio project.

\subsection{Participants}

With regard to demographic characteristics, the participants were quite diverse. Seven of eight DVM students were female, and all of these students were Caucasian. Of the six MLA students, four were male, and four were International students.

\subsection{Curriculum}

The actual spring design studio was a 15-week semester undertaking typical of other COD studio courses. Activities for each of the fifteen weeks are outlined in Table 1. DVM students would be in studio once a week and the MLA students had studios twice a week. This format allowed the MLA students sufficient time to produce designs, ideas, and drawings which were the triggers for discussions with the DVM students on their weekly meetings. We instructed students to find sites within the 160 acre area that were not being optimally used and might accommodate avian, mammalian (including carnivore), and aquatic enclosures being considered in the long term vision for the ZTAU. They undertook a site analysis evaluation that accounted slopes, existing vegetation, infrastructure (electrical, roads, building facilities), waterbodies, open space, drainage, and current land usage (See Figure 1).

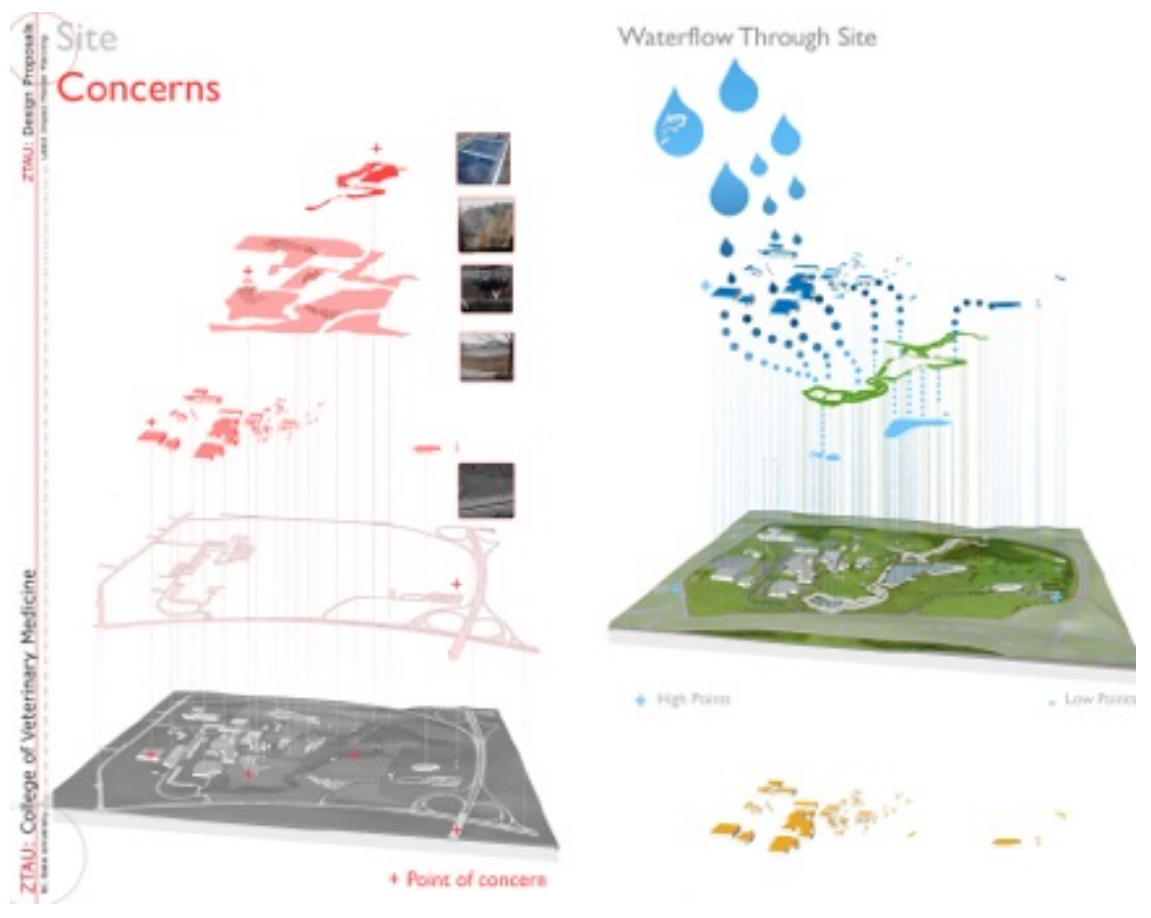

Figure 1. Two examples of detailed analysis drawings developed by students in the course to communicate important issues that needed to be considered in the development of master plans for the campus. The drawing on the left summarizes analysis of access, building placement and existing use zones on the campus. The drawing on the right examines the issues of water flow on the campus with an extraction of building placement below. 
Table 1. Outline of 15 Week Curriculum

\begin{tabular}{ll}
\hline Week & Activities \\
\hline 1 & Project introduction; student introductions; assignment of teams \\
2 & Assign animals to be researched; site analysis for master planning use; creation of existing site model \\
3 & Site analysis mapping by MLA students with input from DVM students \\
4 & Master planning exercise with DVM and MLA students \\
5 & Master plan reviewed by campus landscape architect and MLA department head; DVM students present at \\
& critique \\
6 & Revision of master plan based on comments of jurors and DVM students on site \\
7 & Begin specific animal habitat design; define animals \\
9 & Review with campus landscape architect \\
10 & Spring Break \\
11 & Critique of habitat designs \\
12 & Finalize designs \\
13 & Finalize designs; meet with faculty; finish design \\
14 & Work session \\
15 & Final review to DVM and MLA faculty, campus planners and guests \\
\hline
\end{tabular}

The DVM and MLA instructors narrowed the approach to the project. MLA students were assigned to one of three teams, each working with a different master plan design approach. All three designs options would consider animals, user, teaching, and best of use of existing site. Faculty, students, and animals are at the heart of users in all plans but to varying degree of emphasis. We wanted site plans to help us determine the carrying capacity of the site and maintaining a healthy site for the operation of TAU and ZTAU uses should be stressed by all master plan options. Each team would select one of three approaches:

\subsubsection{Master Plan of Least Impact}

This plan keeps the existing site structure and integrity of existing site design but redefines and reconfigures left over and unused spaces by integrating new ZTAU uses. For this plan one would consider creative and new possibilities for teaching the introduction of alternative zoological species into the currently existing structure of the CVM. This required participation in the transformation of the site into a working TAU + ZTAU with very creative suggestions and guidelines. It would also address existing issues such as soil erosion, and address recommendations.

\subsubsection{Master Plan of Intermediate Impact}

This is a 'what if plan'. In this plan, one can make assumptions about what might be added or removed from the site. Scenarios of possibilities that might enhance the use of the existing landscape for teaching and for the benefit of animal enrichment are developed. For example, what if the equine portion of the TAU were able to be moved to another area of NCSU property? The design process applied by landscape architects allowed for considering different scenarios to test the effects of the master plan if these scenarios were designed into future construction options. The results of testing these scenarios would determine if certain uses remained or were cut out of the final master plan proposal.

\subsubsection{Master Plan of Extreme Impact for Future Benefit}

This approach requires that one develop a master plan that expands the site uses in a dramatic way to remove, add, and reorganize the site completely to fit the teaching needs of alternative species and the future possibilities of expanding with more types of zoological animals. Animal behavior and teaching would be priority in this plan no matter the larger complicated issues of money or politics of history or territoriality of faculty in both the TAU and ZTAU.

\subsubsection{Consolidating into a Master Plan}

Near the midpoint of the semester, after the three different plans had been developed, they were shared with the campus landscape architect and several MLA faculty for consultation. From this point, efforts were focused on developing one master plan from consolidation of positive elements found in one of the three original plans. The iteration process or repeated refinement of the design from feedback of many involved in the project was a matter of much learning as the DVM and MLA's negotiated personal favorites for more broader consent of the larger group of users (campus, CVM, faculty). It is in these negotiated sessions that we saw the DVM students draw (of their own volition) their preferences and ideas while discussing with the MLA students. The DVM students were introduced to 'production' drawing time where the MLA designers were required to create perspectives, diagrams, and plans that visualized for the intended audience images showing the intended proposals for the land.

\section{Results}

\subsection{Course-Level Assessment}

The challenge of the studio was to produce a useful plan that the CVM could use to fundraise and to start discussions 
for the future development of the ZTAU while also providing DVM and MLA students a sufficient introduction to one another's discipline to allow effective interaction. The single combined master plan produced was presented to the administrative body of the CVM and the COD including the Department of MLA in a very strong professional presentation by the course students. They utilized advanced technologies including 270 degree surround projection, high quality animation, and integrated multi-projection to provide visual and audio support for a live presentation. The success of the studio and its presentation was that students expressed a hint that a master plan would necessarily be phased over the next 10-15 years or longer. The plan showed an aggressive addition of 53 acres currently not part of the existing master plan for the CVM. The work was sufficiently detailed to allow for funding options, and it showed options for possibilities the faculty had not considered. The combined studio set into motion a confident first move in deciding what should be the first set of issues to be addressed in the ZTAU development. The final presentation was at such a high level that two encore performances were requested for the university provost and chancellor.

\subsection{Student-level Assessment}

At the end of the semester the design students were interviewed about the studio. Their comments about the studio related to 1) the team environment, 2) the structure of the studio, and 3) the roles and importance of the faculty leading the studio and others involved in the project. Veterinary students were also queried by their faculty member about the experience along similar lines. There was a transformation that occurred over the time frame of the studio in the thinking by the design students and veterinary students.

In the beginning of the course, MLA students began with a very common point of view about the ambiguousness of the inter-professional relationships. Many of their concerns included: Were the veterinary students getting credit for their involvement? Were the design students accountable for incorporating their input? How much should design students really account for in the decision making process of the design? Later in the semester that kind of thinking turned into statements such as "We should have tapped their brain for their ideas much earlier in the process".

The veterinary students were similarly concerned about the boundaries of their roles early on, and how they were expected to interact with the design students. They had been coached prior to the studio and assigned specific species types that they would be expected to be more expert about, but initially they did not feel their expertise was being utilized well by all of the design students. The extreme cultural diversity and to some extent language issues also contributed to this perception. Because of the nature of the scheduling and their primary expertise being more aligned to that of clients for the design students, the veterinary students also initially perceived themselves as invading "occupied" territory where design students had desks and computers and a sense of comfort with the space. For the veterinary students, the simple action of leaving their campus and coming to the studio in the downtown section of the city required major mental reorientation.

The team environment was perceived by design students as both a positive and a negative. For many design students, the frustrations about team work revealed that skill level, personality, and culture all very much impacted how a given student group functioned. As expected, teams that exhibited shared values experienced less frustration, and generally, were more productive. Some students in teams were not experienced with the long hours outside of the normal studio time required to achieve the results, and this resulted in other team members taking on added work. During the design process, ideas are changed and modified based on new information, or new directions from the client. Some design student team members were hurt when their designs changed causing them to sense that their ideas were valued less. The team work became better as the semester progressed when the students began to navigate the socio-political elements of working together. Veterinary students had a different, but in some ways similar experience. They were initially utilized by all three design student teams as resource information sources (clients) but when the project was refined to a single master plan and design student teams were set to specific components of the master plan, DVM students were instructed to work with one of the different design student sub groups on the final master plan development. Throughout this flux in team assignments the DVM students were aware of the leadership of the more experienced design students and tended to seek to align themselves with those individuals.

The structure of the studio or how the studio was managed was frustrating to most of the MLA students. Having to negotiate the schedules of two faculty members rather than one, along with the schedules of the DVM students made meeting times and work times more difficult to identify. The MLA students felt this did not help the production work to advance. Students wanted more continuous availability of feedback and found the necessary weekly scheduling of discussions about novel information from the veterinary side to be an obstacle to smooth work flow. The expectation of the MLA students was to have a very smooth experience over the entire semester. For the veterinary students the whole structure of the studio was novel. They were well aware that the schedule had been modified to make it possible for them to participate, but in the beginning they were very naive about the amount of work going on outside the studio proper or when they were not present. 
It was a new type of project for both students and professors so it was not a perfectly smooth integration. At times students in both professions felt lost, frustrated about what and how they were supposed to communicate, and wondered how to synthesize everything that was being discussed. The design students found that amidst the frustrating elements, there was the valuable lesson of not isolating the user, the animal, and the process that helps them to arrive at an answer. DVM students discovered that they could benefit the process by stepping out of their professional jargon and using the tools of the designers in communicating what they needed to get across. They gravitated to more visual forms of communication, including the picking up of a pencil and sketching on a piece of paper.

The interdisciplinary element of this project was unanimously described by all students as exceptional. At first it was difficult for students to assess what role the interaction of veterinary student and design student might play in the design process in unfolding a design. They discovered it was much more about how they worked to develop ideas in formulating their design. One design student mentioned that they 'tried to squeeze in more things into the design' that they had not considered previously in their work. Across the board, the veterinary students were amazed at the scope of thinking that went on in the studio and took significant pride in having come up with novel and innovative solutions to what a first seemed like a constant barrage of obstacles to develop an exciting master plan that they felt a strong investment in seeing pursued.

Design students were often perplexed with questions of accountability. In particular, which professor had the final say in the decision-making process? One professor often said "yes" to a design idea and then another professor said "no". Whose preference and advice should they heed? The driver for this concern about this more "real world" situation was primarily focused on the students' strong awareness of grades and assessment of their participation would be part of the design student grade. This was less of an issue for the DVM students because they were in a pass-fail participation based grading system for the course. They did, however, hope to positively impress both professors. The professors were not aware of their roles being an issue during the semester, as they had clearly divided the grading responsibilities by discipline, but it was clear this was not well communicated to the students in the beginning of the course. In future collaborations this can be readily addressed in the course introduction.

An additional source of confusion for the design students occurred when the students wondered if there were expectations from the professors that the students were not realizing. They wondered about the boundaries of the professorial roles as the professors seemed to take on roles as teachers, clients, and advisors at different times. The design students felt that this negatively impacted their freedom when they were designing, because it was difficult to discuss the realities of a client's concerns when the client (professor) was always around. In this situation, it was perceived that there was more pressure in the studio than in real life situations when the client was present persistently in the studio class and would reject ideas early in the brainstorming process. This was of course in direct conflict with the students' expressed concerns about wanting constant availability of feedback.

The actual design process was new to the DVM students and they were not present in the long studio production times, so they did not have this perception. They were, however, very chagrined early in the course when the first jury gave them a better perspective of the demands on the design students. They became concerned that they were perhaps "wasting" the time of the "designers" when they were just casually discussing the projects. In reality, they were working like normal clients in those situations, and just did not realize that the design students were using their normal processes for working with clients with them. Basically the student as client model was clear to the design students, and the faculty can benefit the process by stepping out of the client role, and functioning more as a "special teams coach".

\subsection{Faculty Assessment}

The two faculty conducting the course indicated a number of important learning moments among the students. The veterinary professor found the DVM students' reactions to the first jury, where the COD students were critiqued unmercifully about the ideas they presented from the campus landscape architect and the MLA department head particularly informative and very indicative of the challenges of inter-professional collaboration. The DVM students were shocked at the "harshness" of the critiques and apologetic to their colleagues because they had not realized how important their sessions were to the results of the jury. Interestingly, the COD students were adapted to this sort of learning and not at all concerned in this way. What the DVM students perceived as casual conversations in a sense were actually normal process for the COD students who were extracting information and ideas out of the sessions. After the first jury, the dynamic changed. DVM students realized their role was important and that their knowledge base was not shared by their MLA collaborators. They became more intensely engaged in their fact-finding roles. This was further evidenced by their demonstrating the acquisition of key design vocabulary throughout the course. The COD professor observed the DVM students pick up colored pens and pencils and began to draw to communicate with the COD students and found this change suggestive of breakthroughs in the inter-professional collaborative process. This was perceived as a key assimilation moment between the two student groups. Both faculty members were surprised by the degree of 
bonding that occurred between the DVM and COD students and perceived the experience to have significantly broadened students' perspectives.

\section{Discussion}

\subsection{Lessons Learned}

It is no doubt that the interaction was beneficial for all. There are several areas that will require more investigation and adjustment if this kind of collaboration continues. When asked about the studio in the exit interview, the students recounted that if they had a choice, they would prefer that working in teams be the basic structure of the experience. Statements to this effect included: "there is much more learning doing teamwork" and "it is very interesting to work with other professionals... better than designing by one's self".

The best guiding principles for future courses would be to declare early on the situation under which the students would be evaluated in the end, ask students questions about what they might be unsure of in early stages of the undertaking. It would also help to clarify the roles of all participants, and the explanation of the power for decision making should be confronted early in course process. The details of the project operation, however are best left flexible with guidance by faculty to generate team interactions and practices that best suit the demands of the project, the personality of the students, and the time allotted to complete the project.

The fact that the studio work focused on a real project was a major benefit to the success of the course. Most design experiences in a COD are simulated. Thus, when students know they are working on a simulation or a project that likely will not be used, it has the potential to limit creativity and effort. When the project is real, students know that their concepts could form the foundation for a long but major effort that could change the way zoological medicine is taught at the CVM. It is also important that the scope of work for the studio class be on a scale that can realistically be completed and be executed in the time frame of the course. This was an important factor in limiting the scope of this first collaborative studio course to the master planning effort. Original thoughts of pursuing specific site designs after the master planning would have overloaded the students and resulted in lower quality work across the broader scope of the course. In hindsight, it would have been helpful to have students gain some experience in the environments that will be designed before coming into these design experiences. That is, of course, very difficult when environments for ZTAU learning for veterinary students are limited, but it does suggest the possible value of an entry level course for both MLA and DVM students working on smaller scale issues in ZTAU spaces before coming into the more intensive combined studio format. It was also extremely apparent that students should be allowed to take ownership of the course and the project, as this helps foster creativity and keeps students motivated. We were pleasantly surprised by the extreme success of this project based on the feedback of the jurors. We believe making students aware at the beginning of the course that a wide array of audiences may ultimately see the final work will help keep students engaged and putting forth their best efforts.

\subsection{Future Directions and Implications}

The learning outcomes of the interaction were discussed only in the broad terms of enhancing inter-professional interactions, producing ownership and pride in a product, building team work skills, and experience with different thought and problem solving processes prior to starting the two semester effort. Both professors entered their collaboration based on interests in solving the design problems of the ZTAU and had decided to take their students with them on this journey. Philosophical mantras, including "students designing for students" and "utilize land in an environmentally sound manner" provided key guidance along the journey. Along the way during this first effort, and particularly at the end of the spring semester, it was clear that learning experiences based on both semester's activities were abundant. Some modifications in course direction and scope were implemented to enhance those experiences. The next time this collaborative takes place all faculty and prospective students alike will be more cognizant of the learning problems and possibilities available. This experience is the type of experience where learning occurs both as the project flourishes and when failures or setbacks occur. When failures or roadblocks are encountered, engaged students tend to self-realize sub-optimal interactions or processes and are apt to not let those things happen in their professional career. The successes are clear and the students tend to seek out further opportunities to develop similar activities. The effective use of discussion among differing professionals does not happen often in academic settings, but should be encouraged, to improve familiarity of one another's professional role in society. This understanding generates a comfort in knowing what other professionals can offer to make a project more fruitful. We believe this broad inter-professional approach will produce more informed decisions that will offer better environments for people and animals.

The type of collaboration described in this article can be extended to a number of additional scenarios. For example, in the context of design collaborations with veterinary professionals, opportunities exists in veterinary hospitals, classrooms, research buildings, etc. It is very common for many structures to require 10 years of conception before construction begins, and often these works are completed with little creative thought. To continually have teams of 
veterinary experts and professional designers working on creative and effective designs, can enhance the quality and longevity of the eventual structures. In any instance, colleges of veterinary medicine may serve as a potential laboratory for design colleges, resulting in an environment in which members from both veterinary and design disciplines experience mutual benefits.

Of course, it is our hope that the lessons learned from a collaboration between design and veterinary medical students may be beneficial to professionals working in a wide variety of disciplines. Academic disciplines tend to produce "types" by training individuals to share a common vernacular and approaches for exploring problems and finding solutions. Critical thinking, problem solving, communication, teamwork, leadership, and other inter-personal skills are required in virtually every discipline. Although the disciplines presented in this article are quite disparate, we believe many of our lessons learned will be transferrable to a number of interdisciplinary scenarios.

\subsection{Conclusion}

While leading authorities in the business world are discussing new theories for reinventing the work setting, debating the need for change in our business organizations, or taunting business for more innovative influences, academics should consider exploring collaboration and new ways of thinking in a classroom setting. The frustrations that are experienced in collaborations like the one undertaken by the COD and CVM become part of the growing pains in developing what brain authorities consider forming the malleable brain. From this frustration, and even tension, will evolve a new knowledge and way of informing thinking.

\section{Acknowledgements}

The authors would like to thank Robert Massengale and Dr. John Tector for their assistance with this project.

\section{References}

Angelo, T. A., \& Cross, K. P. (1993). Classroom assessment techniques: A handbook for college teachers (2nd ed.). San Francisco: Jossey-Bass.

Hosey, G., Melfi, V., \& Pankhurst, S. (2009). Zoo Animals: Behaviour, Management and Welfare. New York: Oxford University Press.

Interprofessional Education Collaborative Expert Panel. (2011). Core competencies for interprofessional collaborative practice: Report of an expert panel. Washington, D.C.: Interprofessional Education Collaborative.

Johnson, C., \& Grandin, T. (2006). Animals in Translation: Using the Mysteries of Autism to Decode Animal Behavior. New York: Harvest Book.

Kim, M. J., Ju, S. R., \& Lee, L. (2015). A cross-cultural and interdisciplinary collaboration in a joint design studio. International Journal of Art \& Design Education, 34(1), 102-120. http://dx.doi.org/10.1111/jade.12019

Kustritz, M. V. R., Molgaard, L. K., \& Tegzes, J. H. (2013). Frequencies of interactions between veterinarians and other professionals to guide interprofessional education. Journal of Veterinary Medical Education, 40(4), 370-377. doi: 10.3138/jvme.0413-065R

Lee, J. J. (2004). Comparing institutional relationships with academic departments: A study of five academic fields. Research in Higher Education, 45(6), 603-624. http://dx.doi.org/10.1111/jade.12019

Royal, K. D. (2010). Evaluating faculty perceptions of student learning outcomes: A Rasch measurement analysis. Journal of MultiDisciplinary Evaluation, 6(14), 18-31.

Royal, K. D., Eli, J. A., \& Bradley, K. D. (2010). Exploring community college faculty perceptions of student outcomes: Findings of a pilot study. Community College Journal of Research \& Practice, 34(7), 523-540. http://dx.doi.org/10.1080/10668920701827025

Simonds, J. O., \& Starke, B. (2006). Landscape Architecture, Fourth Edition: A Manual of Land Planning and Design. New York: McGraw-Hill.

Whitaker, A. (2014). Incorporation of a stand-alone elective course in animal law within animal and veterinary science curricula. Journal of Veterinary Medical Education, 41(1), 55-59. http://dx.doi.org/10.3138/jvme.0113-001R1

\section{(cc) Br}

This work is licensed under a Creative Commons Attribution 3.0 License. 